\title{
Measurements of diurnal variations and Eddy Covariance (EC) fluxes of glyoxal in the tropical marine boundary layer: description of the Fast LED-CE-DOAS instrument
}

\author{
S. Coburn et al.
}

Correspondence to: R. Volkamer (rainer.volkamer@colorado.edu) 

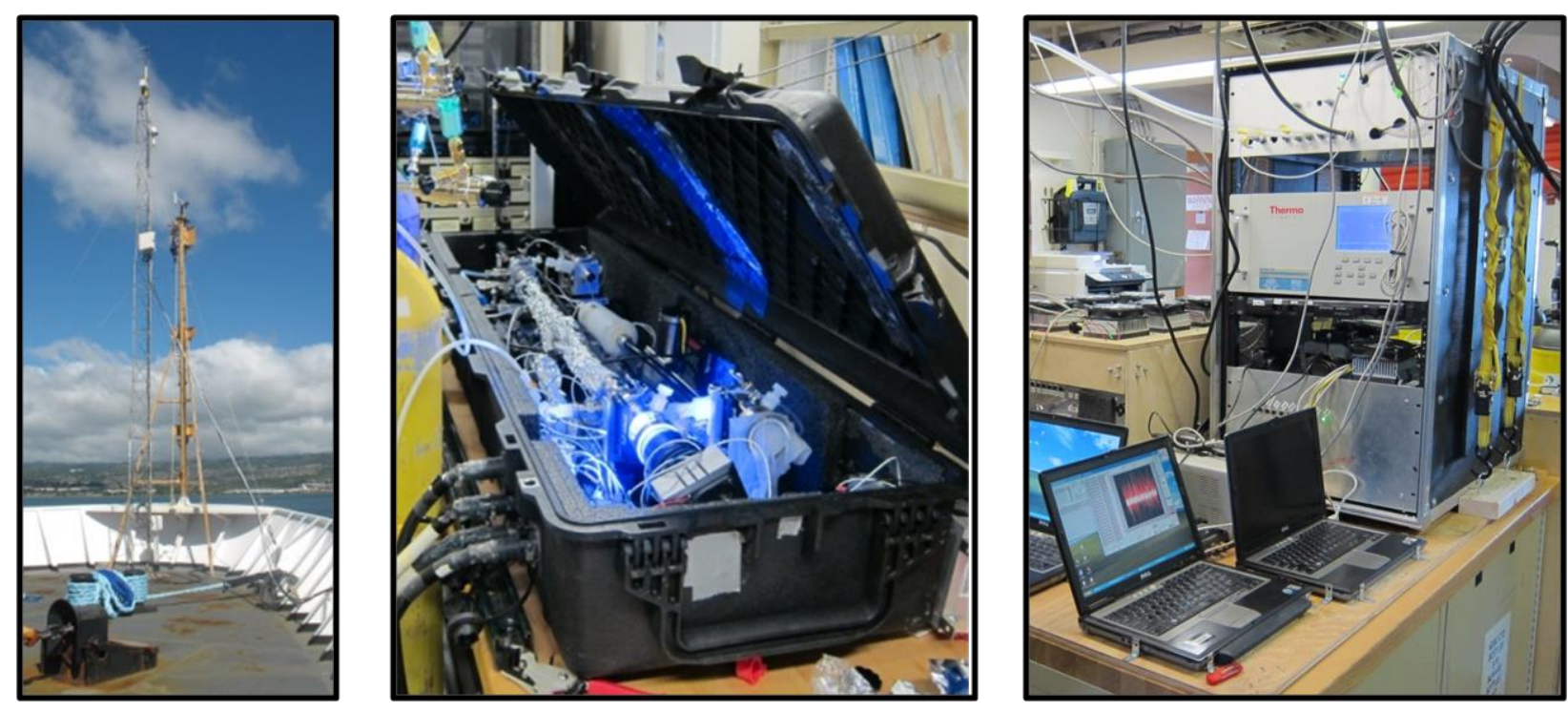

SI Figure 1 Photographs of the instrument set up aboard the RV Ka'imimoana during the

TORERO 2012 field experiment. Left panel shows the instrument inlets, sonic anemometer, and motion system mounted to the jackstaff on the bow of the ship. Middle panel shows the FastLED-CE-DOAS instrument, and the right panel shows the instrument rack containing all of the controlling electronics for the cavity as well as the spectrometer/detector. 


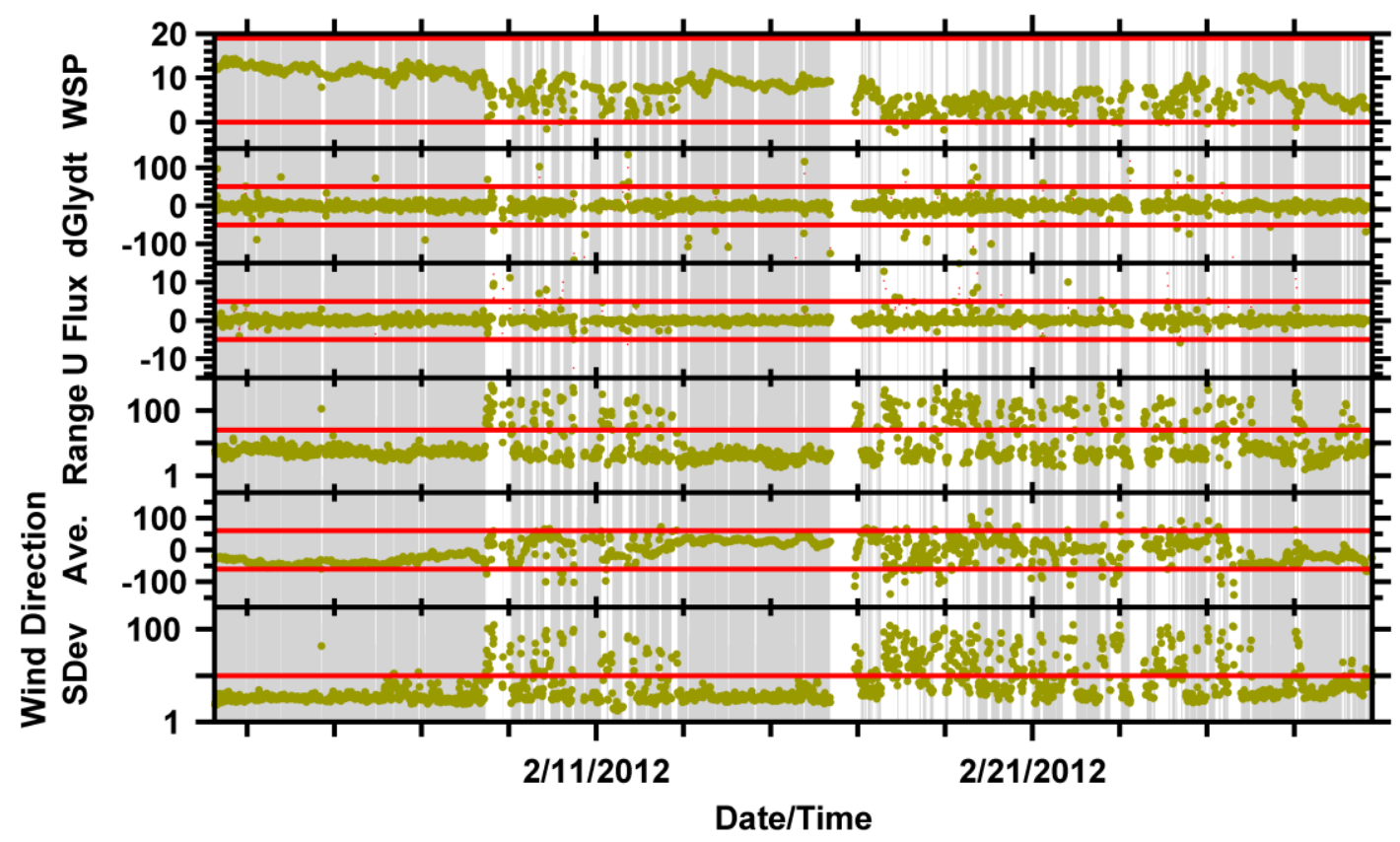

SI Figure 2 Time series of parameters used to filter fluxes. Grey shaded background represents times suitable for flux calculations, determined only by these parameters. Each data point represents a $30 \mathrm{~min}$ average with $50 \%$ overlap to adjacent points. Horizontal red lines indicate the limits for the different filters. 